\title{
Mitgliederversammlung der DEGUM
}

Sehr geehrte, liebe DEGUM-Mitglieder, liebe Kolleginnen und Kollegen,

als aktueller Präsident der DEGUM kommt mir die Ehre zu, Sie ganz herzlich nach Davos einzuladen.

Wie schon vor 3 Jahren findet 2015 das Ultraschall-Dreiländertreffen wieder in Davos statt, ausgerichtet und vorbereitet von einem bewährten Team der Kolleginnen und Kollegen aus der Schweiz unter

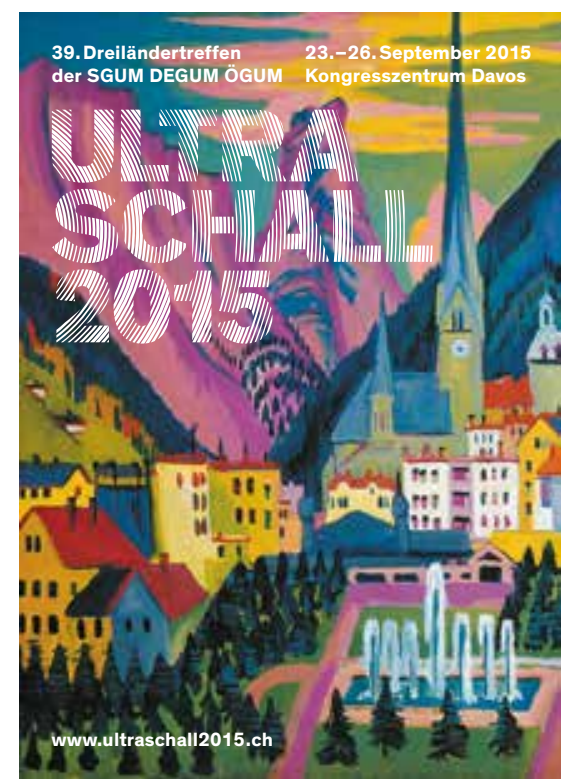

Einbeziehung der österreichischen und deutschen Ultraschaller.

Davos ist wie immer eine Reise wert, die Berge im Spätsommer haben ihren eigenen Charme. Bei einer wachsenden Ultraschall-Fachgesellschaft (die DEGUM hat nun fast 10000 Mitglieder) möchte ich Sie im Namen des gesamten Vorstands und aller Sektionen und Arbeitskreise der DEGUM ganz herzlich zum jährlichen Ultraschall-Dreiländertreffen einladen.

Wie in allen Jahren werden Sie einen Mix von Fortbildungsveranstaltungen und wissenschaftlich neuen Dingen finden, das Vorprogramm ist bereits im Internet einsehbar (www.ultraschall2015.ch).

Daneben wird es, wie bei jedem Dreiländertreffen, auch wieder eine Mitgliederversammlung der DEGUM geben, hier wird der in Innsbruck neu gewählte Vorstand Rede und Antwort zu aktuellen Fragen stehen.

Die DEGUM lebt von ihren Mitgliedern und dient der Verbreitung des Ultraschalls über fachliche Grenzen hinweg. Ich würde mich freuen, wenn Sie Zeit haben und den Weg nach Davos finden, im Namen aller Mitglieder des Vorstands, der Geschäftsstelle und der DEGUM-Akademie grüße ich Sie sehr herzlich,

Ihr Dirk Becker 